\title{
Regional prediction of basin-scale brown trout habitat suitability
}

\author{
SERENA CEOLA \& ALESSIO PUGLIESE \\ Department DICAM, University of Bologna, Bologna, Italy \\ serena.ceola@unibo.it
}

\begin{abstract}
In this study we propose a novel method for the estimation of ecological indices describing the habitat suitability of brown trout (Salmo trutta). Traditional hydrological tools are coupled with an innovative regional geostatistical technique, aiming at the prediction of the brown trout habitat suitability index where partial or totally ungauged conditions occur. Several methods for the assessment of ecological indices are already proposed in the scientific literature, but the possibility of exploiting a geostatistical prediction model, such as Topological Kriging, has never been investigated before. In order to develop a regional habitat suitability model we use the habitat suitability curve, obtained from measured data of brown trout adult individuals collected in several river basins across the USA. The Top-kriging prediction model is then employed to assess the spatial correlation between upstream and downstream habitat suitability indices. The study area is the Metauro River basin, located in the central part of Italy (Marche region), for which both water depth and streamflow data were collected. The present analysis focuses on discharge values corresponding to the 0.1-, 0.5-, 0.9-empirical quantiles derived from flow-duration curves available for seven gauging stations located within the study area, for which three different suitability indices (i.e. $\psi_{10}$, $\psi_{50}$ and $\left.\psi_{90}\right)$ are evaluated. The results of this preliminary analysis are encouraging showing Nash-Sutcliffe efficiencies equal to $0.52,0.65$, and 0.69 , respectively.
\end{abstract}

Key words flow-duration curve; Top-kriging; habitat suitability; brown trout

\section{INTRODUCTION}

The natural streamflow regime of a river and the associated hydraulic features are considered a major controlling factor of stream ecological processes and functions (Power et al. 1995, Poff et al. 1997, Allan and Castillo 2007, Ceola et al. 2013). Evidently, the activity, behaviour and distribution of fluvial species are governed by the environmental conditions within a stream reach (see e.g. Poff and Allan 1995, Bradford et al. 2011), which vary along the river network. Habitat suitability curves are a tool widely employed in stream ecology to describe species habitat preferences: species behaviour and density distribution are expressed as a function of any generic environmental variable, such as flow velocity, water depth, river bed substrate and shear stress (Raleigh et al. 1986, Vismara et al. 2001, Ceola et al. 2014).

We present here an ecological extension of classical hydrological tools (e.g. flow-duration curves) coupled with a geostatistical regional model, such as Top-kriging, to assess the habitat suitability for brown trout (Salmo trutta) in a pre-alpine river basin (Metauro River, Italy). From geomorphologic and hydrologic features we estimate the spatio-temporal variability of water depth as one of the main drivers of brown trout habitat suitability. From discharge measurements corresponding to seven gauging stations along the river network we derive flow-duration curves and, by applying a geomorphic scaling relationship, we compute water depth time series. Then, we employ a habitat suitability curve derived from data (Raleigh et al. 1986) and estimate the temporal sequences of brown trout habitat suitability at the streamflow gauging stations. Finally, we develop a geostatistical model based on the Top-kriging technique (Skøien et al. 2006, Archfield et al. 2013, Pugliese et al. 2013) to examine if a regionalization approach, widely employed in recent studies for the estimation of different hydrological indices in ungauged catchments, may be also applied to an ecological context.

\section{MATERIALS AND METHODS}

\section{Top-kriging}

Top-kriging is a powerful geostatistical procedure (Skøien et al. 2006, Castiglioni et al. 2011) which performs hydrological predictions at ungauged sites along stream networks on the basis of 
the empirical information collected at neighbouring gauging stations. In Top-kriging the spatial interpolation is obtained by a linear combination of the empirical values; therefore, the unknown value of the hydrological index of interest at a prediction location $x_{0}, Z\left(x_{0}\right)$, can be estimated as a weighted average of the variable measured in the neighbourhood as:

$$
\hat{Z}\left(x_{0}\right)=\sum_{i=1}^{n} \lambda_{i} Z\left(x_{i}\right)
$$

where $\lambda_{i}$ is the kriging weight for the empirical value $Z\left(x_{i}\right)$ at location $x_{i}$, and $n$ is the number of neighbouring stations used for interpolation. In equation (1), $\lambda_{i}$ weights can be computed by solving a linear system with the coefficients expressed by the semi-variances between site $i$ and $j$, with $i, j=1, \ldots, n$. A peculiar feature of Top-kriging is to consider the variable $Z$ defined over a non-zero support, fixed with the drainage area. This implies that the semi-variances between empirical values need to be obtained by regularization, that is the smoothing effect of the non-zero support.

\section{Study area and hydrological measurements}

The study area for the analysis is the Metauro River basin above Barco di Bellaguardia, located in the Marche region of Central Italy (see Fig. 1(a) and Castiglioni et al. 2011). The catchment has an average elevation of $560 \mathrm{~m}$ a.s.1.. The climate is pre-alpine continental (typical of the Appennine region) with an average annual precipitation of approximately $1120 \mathrm{~mm}$ and average temperature of nearly $12.4^{\circ} \mathrm{C}$. Daily discharge measurements from seven gauging stations located within the study area (Fig. 1(a) and Table 1) are available from 1920 to 2000 (SIMN). For each of these stations, we generated the flow-duration curves (Vogel and Fennessey 1994) from the recorded discharge time series (Fig. 1(b)). Note that the proposed analysis mainly focuses on discharge values corresponding to the $0.1-, 0.5$-, 0.9 -empirical quantiles (i.e. high, median and low flows, respectively, Table 1), aiming at an objective and synthetic analysis of some of the most relevant features of river flow regime (Jowett and Duncan 1990).
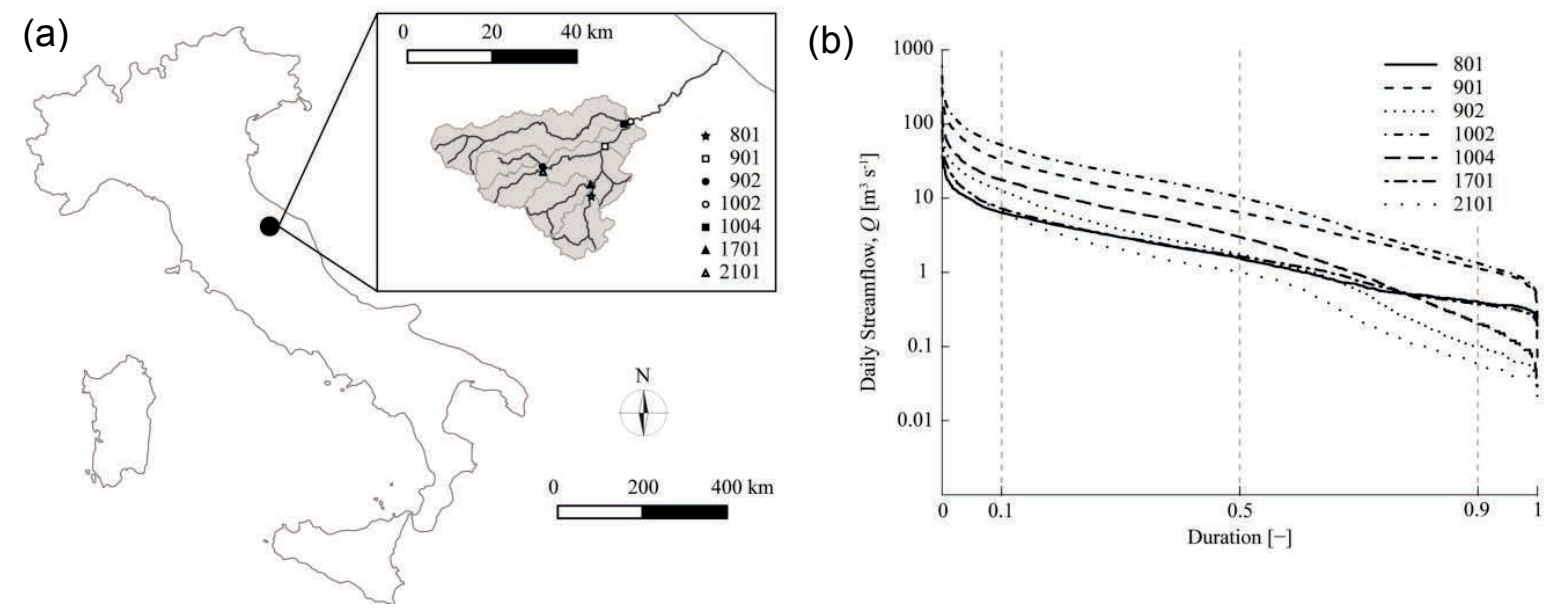

Fig. 1 (a) Study area: Metauro River closed at Barco di Bellaguardia (ID = 1002). (b) Flow-duration curves from measured daily discharge temporal sequences corresponding to the seven gauging stations along the Metauro River. Grey dashed vertical lines identify the 0.1-, 0.5-, 0.9-empirical quantiles.

\section{Brown trout habitat suitability}

Brown trout (Salmo trutta) is one of the most common fish in the Metauro River (Lorenzoni et al. 2010), and its habitat suitability is influenced by stream environmental conditions. In particular, water depth is a major controlling factor of brown trout habitat suitability (Raleigh et al. 1986, Vismara et al. 2001). 
Table 1 Summary of the key geomorphologic, hydrologic and stream ecological features for the seven subbasins of the Metauro River.

\begin{tabular}{|c|c|c|c|c|c|c|c|c|c|c|c|c|}
\hline \multirow[b]{2}{*}{ ID } & \multirow{2}{*}{$\begin{array}{l}\text { Catchment } \\
\text { Gauging station } \\
\text { name }\end{array}$} & \multirow{2}{*}{$\begin{array}{c}\text { Drainage } \\
\text { area }\left(\mathrm{km}^{2}\right) \\
\mathrm{A} \\
\end{array}$} & \multirow{2}{*}{$\begin{array}{l}\text { Reach } \\
\text { length }(\mathrm{km}) \\
\mathrm{L} \\
\end{array}$} & \multicolumn{3}{|c|}{ Discharge $\left(\mathrm{m}^{3} \mathrm{~s}^{-1}\right)$} & \multicolumn{3}{|c|}{ Water depth (m) } & \multicolumn{3}{|c|}{$\begin{array}{l}\text { Habitat } \\
\text { suitability (-) }\end{array}$} \\
\hline & & & & $\mathrm{Q}_{10}$ & $\mathrm{Q}_{50}$ & $\mathrm{Q}_{90}$ & $\mathrm{~d}_{10}$ & $\mathrm{~d}_{50}$ & $\mathrm{~d}_{90}$ & $\psi_{10}$ & $\psi_{50}$ & $\psi_{90}$ \\
\hline 801 & Foci & 123.7 & 16.9 & 6.35 & 1.56 & 0.40 & 0.76 & 0.54 & 0.39 & 0.98 & 0.73 & 0.52 \\
\hline 901 & $\begin{array}{l}\text { Acqualagna } \\
\text { Piobbico@ }\end{array}$ & 611.9 & 56.3 & 32.80 & 6.44 & 1.14 & 1.12 & 0.76 & 0.50 & 0.71 & 0.98 & 0.67 \\
\hline 902 & $\begin{array}{l}\text { Candigliano } \\
\text { Barco di }\end{array}$ & 186.1 & 33.6 & 12.60 & 1.76 & 0.10 & 0.89 & 0.56 & 0.28 & 0.99 & 0.75 & 0.39 \\
\hline 1002 & Bellaguardia & 1040.3 & 75.7 & 51.86 & 10.40 & 1.34 & 1.24 & 0.85 & 0.52 & 0.52 & 1.00 & 0.70 \\
\hline 1004 & Calmazzo & 374.7 & 74.3 & 17.70 & 3.01 & 0.20 & 0.96 & 0.63 & 0.33 & 0.92 & 0.85 & 0.45 \\
\hline 1701 & $\begin{array}{l}\text { Cagli } \\
\text { Piobbico@ }\end{array}$ & 125.7 & 26.6 & 7.26 & 1.64 & 0.37 & 0.78 & 0.55 & 0.38 & 0.99 & 0.74 & 0.52 \\
\hline 2101 & Biscuvio & 94.9 & 19.0 & 6.81 & 1.01 & 0.06 & 0.77 & 0.49 & 0.25 & 0.99 & 0.65 & 0.36 \\
\hline
\end{tabular}

Here, we used the habitat suitability curve obtained from measured data of brown trout adult individuals collected along several USA river catchments (Raleigh et al. 1986). This curve presents a hump-shaped trend with a maximum at $d=1 \mathrm{~m}$ (Fig. 2). Suitability values lie between 0 and 1 , where $\psi=0$ represents the habitat state characterized by the absence of brown trout and $\psi=1$ corresponds to the maximum species density condition. Moving from this habitat suitability curve, we performed a fitting procedure to derive the following analytical model (Fig. 2, black line) describing the relationship between habitat suitability $\psi$ and water depth $d$ as:

$$
\psi=\frac{p_{1} d^{2}+p_{2} d+p_{3}}{d^{3}+q_{1} d^{2}+q_{2} d+q_{3}}
$$

where the coefficients are: $p_{1}=-924.2, p_{2}=1843, p_{3}=299.5, q_{1}=3889, q_{2}=-5894, q_{3}=3421$.

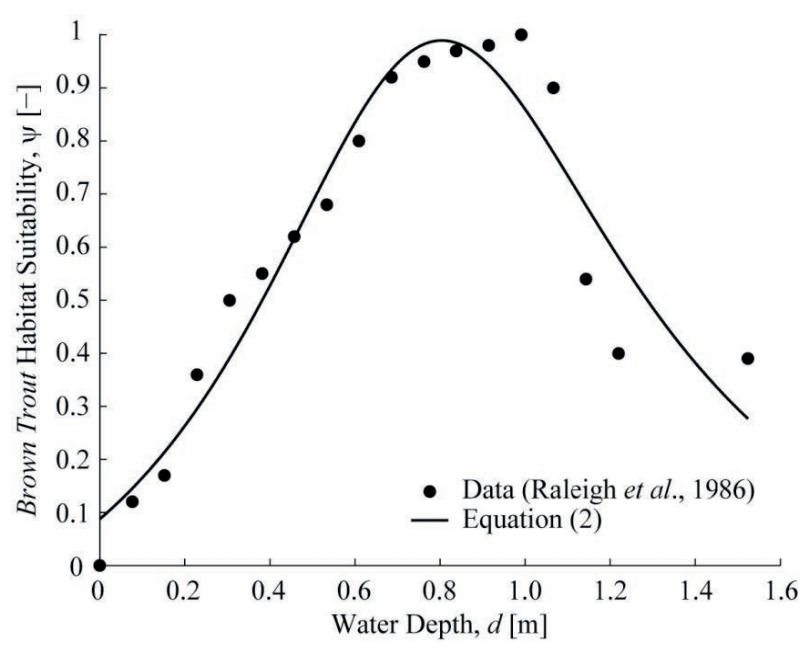

Fig. 2 Habitat suitability curve for brown trout: comparison between data (Raleigh et al. 1986) and the analytical model expressed by equation (2).

\section{RESULTS}

\section{Basin-scale analysis of water depth}

Fluvial processes, in particular discharge, flow and sediment properties, which vary along the stream network, influence the river's geomorphology (Leopold et al. 1964). A geomorphic scaling relationship describing the variability of water depth along the river network in a downstream direction, as a function of discharge reads, is given as follows (Leopold et al. 1964): 


$$
d=c Q^{f}
$$

where $c$ and $f$ are coefficients. In this context, we used discharge and water level measurements collected by the Civil Protection Agency (Protezione Civile Regione Marche) from 2003 to 2011 for the gauging stations of Acqualagna and Lucrezia (i.e. located slightly downstream Barco di Bellaguardia) to derive the coefficients values in equation (3) as $c=0.49 \mathrm{~s}^{\mathrm{f}} \mathrm{m}^{1-3 \mathrm{f}}$ and $f=0.24$. From the estimated scaling relation, we evaluated the temporal sequences of water depth for the seven gauging stations and computed the 0.1-, 0.5-, 0.9-quantiles (Table 1).

\section{Basin-scale analysis of brown trout habitat suitability}

By coupling equations (2) and (3), from the spatial distribution of water depth along the Metauro River network we assessed the corresponding brown trout habitat suitability (Table 1, Figs 3 and 4). Interestingly, the sub-basins closed at the gauging stations of Piobbico @ Biscuvio, Piobbico (a) Candigliano, Foci, Cagli and Calmazzo present empirical values (i.e. derived from water depth data) of brown trout habitat suitability that decrease from $\psi_{10}$, to $\psi_{50}$ and to $\psi_{90}$. Conversely, the sub-basins closed at Acqualagna and Barco di Bellaguardia (i.e. the two largest ones) show a maximum brown trout habitat suitability at the 0.5 -quantiles, corresponding to median discharge and water depth values.

Top-kriging is applied routinely through a leave-one-out cross-validation algorithm in order to assess for each and every site a comparison between the empirical and predicted habitat suitability values. A good agreement emerges from the results, thus revealing an overall fair performance of the proposed regionalization technique. More specifically, for the 0.1-quantile of brown trout habitat suitability $\left(\psi_{10}\right)$, which corresponds to high flow conditions, the empirical and prediction values range between 0.52 and 0.99 . The observed spatial trend from the empirical values is well reproduced by the Top-kriging, obtaining a good prediction performance with a Nash-Sutcliffe Efficiency (NSE) equal to 0.52, although some discrepancies between empirical and predicted values may emerge. In this case, a decreasing trend with increasing drainage area and water depth is revealed, mainly related to water depth values $\left(d_{10}\right)$ that lie on the decreasing limb of the habitat suitability curve (see equation (2), Table 1 and Fig. 2).

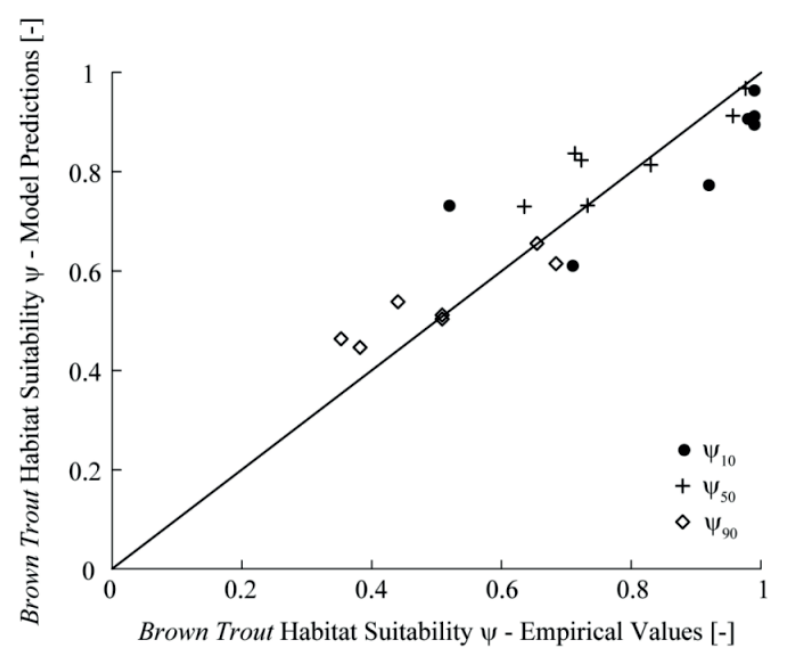

Fig. 3 Brown trout habitat suitability: scatterplot of 0.1-, 0.5-, 0.9-quantiles of empirical values (derived from water depth values) against model predictions from cross-validation (equations (2) and (3)).

Conversely, for the 0.5- and 0.9-quantiles (median and low flow conditions, respectively), the empirical values and model predictions of brown trout habitat suitability increase in the downstream direction. Here the water depth ranges are $0.54-0.85 \mathrm{~m}$ and $0.25-0.52 \mathrm{~m}$, respectively 


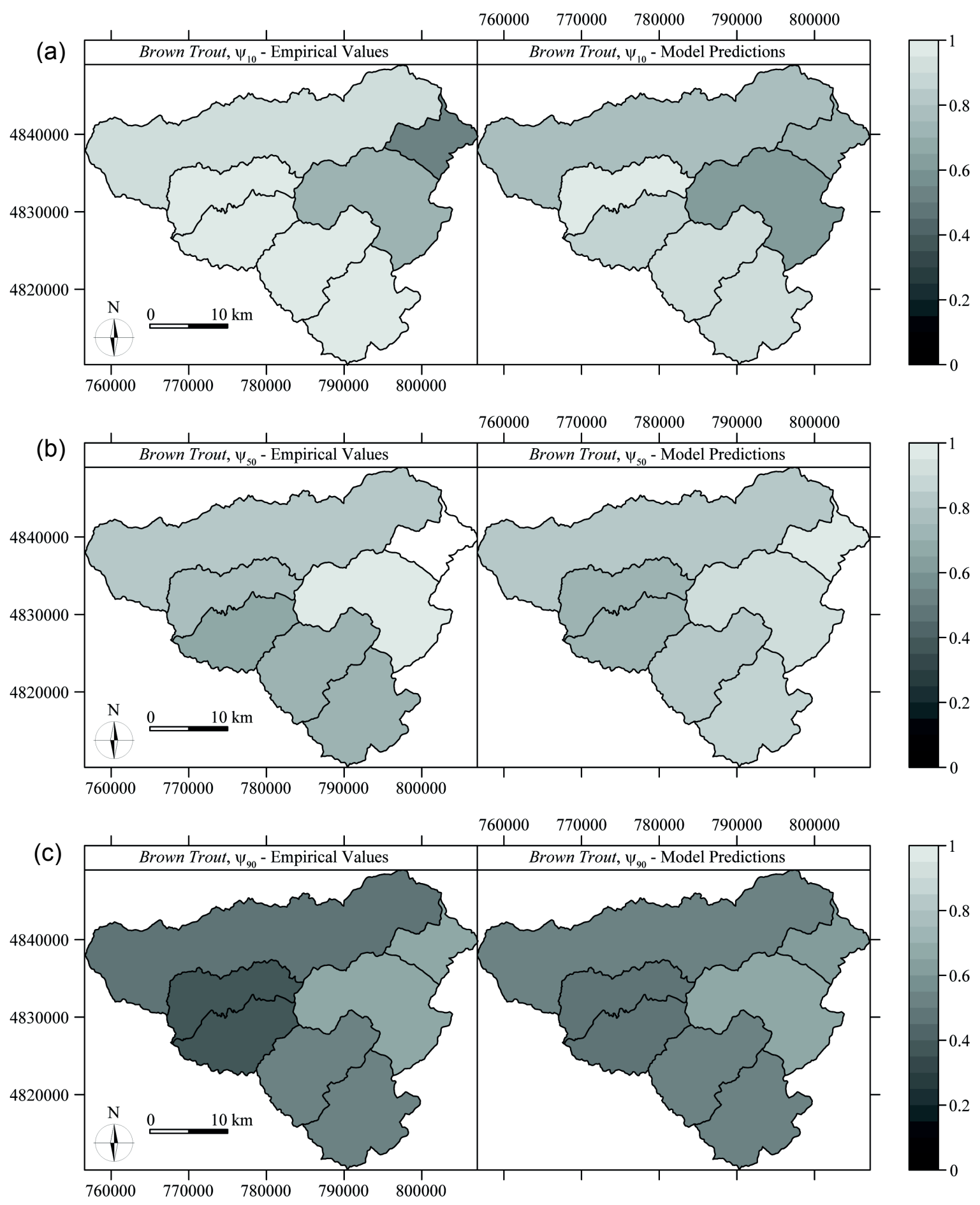

Fig. 4 Brown trout habitat suitability maps for the seven sub-basins in the Metauro River. Comparison of empirical values (i.e. derived from water depth values) against model predictions from crossvalidation (equations (2) and (3)) for: (a) 0.1-quantile, (b) 0.5-quantile, (c) 0.9-quantile.

(Table 1), thus lying on the rising limb of the habitat suitability curve (Fig. 2). In these cases, Topkriging obtains fairly good performances, showing NSE equal to 0.65 and 0.69 , respectively. It is interesting to point out that $\psi_{50}$ presents overall the largest values of habitat suitability, when compared to $\psi_{10}$ and $\psi_{90}$, whereas $\psi_{90}$ shows very good regional model performances (Fig. 4). 


\section{CONCLUSIONS}

In this paper we performed a spatial assessment of brown trout habitat suitability along the Metauro River, primarily influenced by hydrologic and geomorphologic features. The preliminary analysis reported here shows a reasonably successful application of classical hydrological tools, such as flow-duration curves and a regionalization technique (Top-kriging) for ecological purposes. From our preliminary results, we infer that Top-kriging can be reasonably employed for stream ecology purposes, where missing or total lack of observations occur. Habitat suitability maps derived from Top-kriging may provide a fundamental tool for the assessment of the ecological integrity of a river basin and its sub-basins.

\section{REFERENCES}

Allan, J. D. and Castillo, M. (2007) Stream Ecology: Structure and Function of Running Waters. Springer, Dordrecht, The Netherlands.

Archfield, S. A., et al. (2013) Topological and canonical kriging for design flood prediction in ungauged catchments: an improvement over a traditional regional regression approach? Hydrology and Earth System Sciences 17(4), 1575-1588, doi:10.5194/hess-17-1575-2013.

Bradford, M. J., et al. (2011) Test of an environmental flow release in a British Columbia river: does more water mean more fish? Freshwater Biology 56, 2119-2134, doi:10.1111/j.1365-2427.2011.02633.x.

Castiglioni, S., et al. (2011) Smooth regional estimation of low-flow indices: physiographical space based interpolation and topkriging, Hydrology and Earth System Sciences, 15 715-727, doi:10.5194/hess-15-715-2011.

Ceola, S., et al. (2013) Hydrologic variability affects invertebrate grazing on phototrophic biofilms in stream microcosms, $P L o S$ $O N E$ 8(4), e60629, doi: 10.1371/journal.pone.0060629.

Ceola, S., et al. (2014) Hydrologic controls on basin-scale distribution of benthic invertebrates, Water Resources Research, 50, doi: 10.1002/2013WR015112.

Jowett, I. G. and Duncan, M. J. (1990) Flow variability in New Zealand rivers and its relationship to in-stream habitat and biota, New Zealand Journal of Marine and Freshwater Research 24, 305-317, doi:10.1080/00288330.1990.9516427.

Leopold, L., Wolman, M. and Miller, J. (1964) Fluvial Processes in Geomorphology. Freeman, San Francisco, California.

Lorenzoni, M., et al. (2010) La fauna ittica e i corsi d'acqua dell'Umbria - Sintesi delle carte ittiche regionali dal 1986 al 2009 , Regione Umbria, Perugia, pp. 288.

Poff, N. L and Allan, J .D. (1995) Functional organization of stream fish assemblages in relation to hydrological variability, Ecology 76(2), 606-627, doi:10.2307/1941217.

Poff, N. L., et al. (1997) The natural flow regime. Bioscience 47(11), 769-784, doi:10.2307/1313099.

Power, M. E., et al. (1995) Hydraulic food-chain models. Bioscience 45(3), 159-167, doi:10.2307/1312555.

Protezione Civile Regione Marche, http://protezionecivile.regione.marche.it/.

Pugliese, A., Castellarin A., and Brath, A. (2013) Geostatistical prediction of flow-duration curves, Hydrology and Earth System Sciences Discussions 10(11), 13053-13091, doi:10.5194/hessd-10-13053-2013.

Raleigh, R. F., Zuckerman, L. D., and Nelson, P. C. (1986) Habitat suitability index models and instream flow suitability curves: brown trout. Biological report 82(10.124) Fish and Wildlife Service, U.S. Department of the Interior.

Skøien, J. O., Merz, R., and Blöschl, G. (2006) Top-Kriging - Geostatistics on stream networks, Hydrology and Earth System Sciences 10(2), 277-287, doi:10.5194/hess-10-277-2006.

SIMN, Servizio Idrografico e Mareografico Nazionale, Genio Civile del Ministero dei Lavori Pubblici, Italia.

Vismara, R., et al. (2001) Habitat suitability curves for brown trout (Salmo Trutta Fario L.) in the river Adda, Northern Italy: comparing univariate and multivariate approaches, Regulated Rivers: Research \& Management 17, 37-50, doi: 10.1002/1099-1646(200101/02)17:1<37::AID-RRR606>3.0.CO;2-Q.

Vogel, R. and Fennessey, N. (1994) Flow-duration curves. 1. New interpretation and confidence-intervals, Journal of Water Resources Planning and Management-ASCE 120(4), 485.504, doi:10.1061/(ASCE)0733-9496(1994)120:4(485). 